\title{
ethic@ @ \\ THEODOR W. ADORNO: CONTRIBUIÇÕES À REFLEXÃO SOBRE FORMAÇÃO, DEMOCRACIA E AUTORITARISMO
}

\author{
THEODOR W. ADORNO: CONTRIBUTIONS TO THE REFLECTION \\ ON EDUCATION, DEMOCRACY AND AUTHORITARIANISM
}

\author{
FRANCIELE BETE PETRY ${ }^{1}$ \\ (UFSC/Brasil)
}

\begin{abstract}
RESUMO
O artigo tem como objetivo discutir a tarefa ética e política da educação nos textos de Theodor W. Adorno reunidos na edição Educação e emancipação. Pretende-se mostrar que a concepção de formação defendida por Adorno se vincula à defesa de uma sociedade democrática. Contudo, levando em consideração sua crítica aos limites à emancipação, que é condição da democracia, a tarefa formativa se desenvolve de uma forma negativa como interrupção de um processo histórico com potencial para gerar novas catástrofes. A educação pode ser um meio para se opor ao autoritarismo e buscar dissolver as condições que levariam à repetição da barbárie, ainda que não possa ser considerada uma ferramenta para a transformação radical da sociedade. O texto discute o modo como Adorno concebe a tarefa formativa, sua influência na constituição da subjetividade e sua possibilidade de proporcionar ao sujeito experiências de abertura e de mediação com a realidade. Na atualidade, a contribuição de Adorno se mostra fundamental para a reflexão sobre as relações entre democracia, autoritarismo e educação.
\end{abstract}

Palavras-chave: Educação; Formação (Bildung); Democracia; Autoritarismo.

\begin{abstract}
The paper aims to discuss the ethical and political task of education in Theodor $W$. Adorno's texts published in Erziehung zur Mündigkeit. It will be intended to present that the conception of education (Bildung) defended by Adorno is related to the defense of a democratic society. However, considering Adorno's criticism of the limits to emancipation that is a condition for democracy, the formative task is considered in a negative way as an interruption of the historical process that could generate new catastrophes. Education can work against authoritarianism and seek to dissolve the conditions that would lead to the repetition of barbarism, even though it cannot be considered a tool for radical transformation of society. The paper discusses the way Adorno conceives formative process, its influence on subjectivity and its possibility of providing subjects with open and mediated experiences of reality. Nowadays, Adorno's ideas are fundamental for understanding the relation between democracy, authoritarianism and education.
\end{abstract}

Keywords: Education; Formation (Bildung); Democracy; Authoritarianism. 


\section{Introdução}

É inegável a importância que a educação possui nos processos de transformação social. Contudo, sem que se estabeleça o sentido do próprio conceito de educação ou de transformação social, a afirmação é um tanto geral e vazia. Dentro da tradição do pensamento filosófico desde a Antiguidade até o início do século XX, conforme a interpretação de Honneth (2013), pensar a educação como parte do esforço de teorização política sobre a sociedade era algo comum. Basta lembrarmo-nos da obra de Platão e Rousseau para termos exemplos claros dessa vinculação. O século XX, porém, seria marcado por uma separação entre as teorias políticas da democracia e a educação. Para Honneth (2013), Dewey ainda teria formulado a ideia de uma educação democrática a partir da Filosofia, mas o tema desde então passou a ser tratado pela Pedagogia. Podemos observar, mais recentemente, porém, o trabalho de Nussbaum (2015) na defesa de uma educação para a cidadania global com foco na importância das artes e das humanidades, as quais seriam fundamentais para a preservação das sociedades democráticas. Adorno não está inserido, de imediato, nessa linha argumentativa, já que a importância de sua reflexão está frequentemente mais associada à crítica cultural e aos contextos de formação do que à defesa explícita de um projeto acerca do entrelaçamento entre democracia e educação ${ }^{2}$. Em função da radicalidade de sua crítica e de seu diagnóstico de tempo, a contribuição de Theodor W. Adorno ao tema se dá de forma negativa, mas não menos relevante.

A partir de uma interpretação conjunta dos textos sobre a educação reunidos na edição Educação e emancipação, os quais apresentam intervenções de Adorno, como entrevistas e conferências, realizadas desde o final da década de 1950 e, principalmente, durante a década de 1960, busca-se apresentar os pontos em que a crítica à formação se conecta, de forma interna, à reflexão sobre a democracia, bem como sobre os limites que ambas enfrentam ${ }^{3}$. $O$ artigo pretende discutir as restrições que Adorno atribui à educação e que a tornam um meio frágil de fortalecer a democracia. É possível atribuir a ela, porém, uma tarefa relevante de se contrapor às tendências autoritárias presentes nos indivíduos por meio do compromisso ético e político assumido por todos aqueles que, envolvidos com a educação, manifestam apreço à democracia e à autonomia que ela requer. 


\section{Os limites de uma educação para a democracia}

Em suas reflexões sobre a educação, Adorno mostra como a resistência à dominação e a um totalitarismo potencialmente existente na sociedade é precariamente possível na esfera subjetiva. A despeito da grandiosidade da tarefa expressa na famosa afirmação de que "A exigência que Auschwitz não se repita é a primeira de todas para a educação" (ADORNO, 2003, 119), considerada por Adorno uma espécie de novo imperativo categórico, não cabe à educação colocar-se em uma posição de ser a responsável pela transformação social, tanto porque não está sob seu alcance as condições objetivas necessárias, quanto porque sua tarefa não é propriamente a de uma transformação. Como ele afirma em Educação após Auschwitz, de 1965, "é extremamente limitada a possibilidade de mudar os pressupostos objetivos, isto é, sociais e políticos que geram tais acontecimentos" (ADORNO, 2003, 121), trata-se, antes, da educação buscar interromper processos históricos, colocar um freio na história que poderia fazer de Auschwitz, como afirma Skirke, a última das catástrofes desse tipo (SKIRKE, 2020). Assim, só restaria atuar na esfera subjetiva, o que não traria, no entanto, consequências para uma ruptura da ordem social $^{4}$.

Na entrevista intitulada Educação - para quê?, de 1966, Adorno afirma que a organização do mundo "exerce uma pressão tão imensa sobre as pessoas, que supera toda a educação. Seria efetivamente idealista no sentido ideológico se quiséssemos combater o conceito de emancipação sem levar em conta o peso imensurável do obscurecimento da consciência pelo existente" (ADORNO, 2003, 143) ${ }^{5}$. A crítica de Adorno permite-nos observar como discursos que defendem a educação como o principal instrumento de uma transformação social podem ser ideológicos, já que desprezam a força com que condições sociais, políticas e econômicas reproduzem a ordem social e atuam, mais do que a própria educação, na formação da subjetividade.

Adorno considera os potenciais educacionais, portanto, não em um sentido idealizado, mas a partir de um diagnóstico sobre a sociedade. Este, tal como é apresentado na palestra conferida em 1959, O que significa elaborar o passado, é problemático o suficiente para não impulsionar, mesmo que apenas na esfera subjetiva, alguma forma de resistência:

Considero a sobrevivência do nacional-socialismo na democracia como potencialmente mais ameaçadora do que a 
sobrevivência de tendências fascistas contra a democracia. A corrosão por dentro representa algo objetivo; e as figuras ambíguas que efetivam o seu retorno só o fazem porque as condições lhes são favoráveis (ADORNO, 2003, 30).

Para Adorno, a presença de tais tendências se dá em função da vinculação intrínseca entre civilização e repressão, tão bem caracterizada por Freud6, quanto pelo aprofundamento da dominação em termos econômicos, políticos e sociais. A educação, inclusive, participa da dominação social e não é por acaso que muitas de suas expressões ao longo da história são exemplos de dor e de sofrimento imputados às crianças e aos jovens nos seus processos de adaptação à cultura. Adorno reconhece a tarefa de adaptação que a educação necessita ter, mas afirma que ela também precisa ser um contraponto à sociedade tal como está organizada, ou seja, precisa ser uma forma de resistência em relação ao existente. $\mathrm{Na}$ mesma entrevista citada acima, Adorno afirma:

A educação seria impotente e ideológica se ignorasse o objetivo de adaptação e não preparasse os homens para se orientarem no mundo. Porém ela seria igualmente questionável se ficasse nisto, produzindo nada além de well adjusted people, pessoas bem ajustadas, em consequência do que a situação existente se impõe precisamente no que tem de pior (ADORNO, 2003, 143).

É por isso que, segundo ele, o conceito de educação carrega uma ambiguidade. Como mencionado, a educação não teria, segundo Adorno, a capacidade de contribuir de forma radical para a transformação da sociedade, mas desempenharia um papel importante no sentido de frear as tendências que atuam provocando nos sujeitos conformismo e adaptação ao existente ou, ainda, a naturalização de fenômenos sociais. Assim, sua tarefa consistiria em promover, principalmente, resistência à realidade, ainda que também atue no sentido da adaptação indispensável à vida em sociedade.

Se Adorno está um pouco à margem de estudos com foco nas relações entre democracia e educação, algumas passagens da entrevista Educação - para quê? podem situá-lo como um pensador com relevante contribuição ao tema. Sua concepção de educação envolve a ideia de que ela produz uma consciência verdadeira, tarefa que se coloca como exigência política no contexto das sociedades democráticas: "uma democracia com o dever de não apenas funcionar, mas operar conforme seu conceito, demanda pessoas emancipadas. Uma democracia efetiva só pode ser imaginada 
enquanto uma sociedade de quem é emancipado" (ADORNO, 2003, 142). Adorno vincula sua concepção de emancipação, que move o processo formativo, mas não de forma idealizada, à produção de uma consciência capaz de identificar as relações de dominação social bem como as ideologias que as sustentam e, nessa atitude, capaz também de resistir a elas. A formação implica uma forma de conscientização que emerge sob a marca da organização social, ou seja, considerando o diagnóstico de Adorno de uma sociedade em que a vida se encontra tendencialmente reificada, a educação pode atuar no sentido de frear tal movimento em termos subjetivos na medida em que se apresenta como autorreflexão crítica (ADORNO, 2003). Essa forma de compreender o processo formativo faz de Adorno um crítico do conceito tradicional de formação (Bildung) do idealismo alemão. ${ }^{7}$ Isso porque, como explica Stojanov, a Bildung é comumente associada ao encontro do eu com o mundo em um sentido que transcende as interações sociais e as instituições (STOJANOV, 2012). Já Adorno a vincula aos processos e estruturas sociais, de forma que utiliza também, como um aliado potencial da formação, a educação no sentido de Erziehung, a qual se refere, tradicionalmente, a contextos empíricos. Assim, quando Adorno se refere a uma aposta possível na educação, faz referência a ela de forma mais geral, não em termos de um projeto pedagógico, mas como compromisso ético e político assumido por educadores que, indiretamente, poderá se refletir na esfera institucional. De maneira análoga, é possível dizer que a aposta da educação, tal como a concebe Adorno, não se dirige exatamente, nos termos de uma formulação positiva, à constituição de uma sociedade democrática, mas, negativamente, à recusa em perpetuar e fortalecer os traços autoritários presentes na sociedade, os quais se desdobram em termos subjetivos, e que poderiam abrir caminho para a repetição da barbárie.

É considerando a influência dos processos sociais na constituição da subjetividade que a formação, para Adorno, se realizará por um duplo movimento: por um lado, ela possibilitaria, por meio da autorreflexão, reconhecer as forças sociais que atuam no sujeito, ao mesmo tempo em que, por outro, auxilia a compreender a raiz objetiva de tais forças. Esse movimento duplo é vital para a democracia, como se discutirá adiante. Para que ele tenha lugar, é importante também a contribuição dada pela Psicanálise, pois ela permitiria examinar os traços que constituem a subjetividade em um determinado contexto histórico. Os estudos sobre a personalidade autoritária referidos por Adorno em suas reflexões sobre a educação (ADORNO, 2003) o levam a defender a ideia de que a questão da formação não se reduz ao tipo de conhecimento ou de conteúdos disponibilizados aos indivíduos, mas sobretudo à forma como eles compõem 
o espaço da reflexão, ou a impedem. Vale lembrar que também o fenômeno da indústria cultural opera nessa dimensão, mobilizando aspectos inconscientes e que fortalecem os mecanismos de dominação interna. Os processos formativos, nesse sentido, atuam não como mera contraposição à dinâmica impulsionada pela indústria cultural, mas como sua negação, dissolvendo os elementos que amparariam a influência tão forte da realidade sobre o sujeito.

É importante lembrar, ainda, que apesar da importância da Psicanálise para uma formação contra o autoritarismo, Adorno não reduz o problema da permanência ou retorno do fascismo a aspectos psicológicos. A vinculação entre educação e "inflexão em direção ao sujeito", para usar a bem conhecida expressão da conferência Educação após Auschwitz, se dá pela impossibilidade de que outro caminho esteja dado ou, como diz Adorno, porque "os demais momentos, mais essenciais, em grande medida escapam à ação da educação, quando não se subtraem inteiramente à interferência dos indivíduos" (ADORNO, 2003, 123). Nesse sentido, mais do que formar para a democracia, a qual requer emancipação social, a educação tem um papel de voltar-se contra as forças autoritárias presentes na sociedade e que constituem a subjetividade.

\section{Experiência e formação}

Nas reflexões sobre a educação desenvolvidas por Adorno, o conceito de experiência é fundamental para a possibilidade de resistência às diferentes formas de dominação. A experiência é compreendida como momento de mediação conceitual com a realidade. É por ela que ocorre o movimento dialético entre sujeito e objeto. A experiência é também, por isso, o espaço da formação em um sentido bastante estrito: se há experiência, há um processo formativo em ação. A crítica de Adorno à semiformação e à ação exercida pelo fenômeno da indústria cultural na subjetividade são uma espécie de avesso da experiência, ou seja, são formas reificadas pelas quais a relação do indivíduo com a sociedade é estabelecida ou, como formula O'Connor, "experiência reificada é uma distorção da interação sujeito-objeto: não é, enquanto tal, uma experiência genuína" (O'CONNOR, 2013, 55).

A experiência é marcada pela consciência, esta que Adorno remete ao "pensar em relação à realidade, ao conteúdo - a relação entre as formas e estruturas de pensamento do sujeito e aquilo que este não é" (ADORNO, 2003, 151). É nesse sentido que Adorno associa a consciência, o pensamento, à capacidade de fazer experiências (ADORNO, 2003). Sua crítica à experiência, de inspiração benjaminiana, aponta para um 
empobrecimento da capacidade de pensar, substituída por formas mais simples de estabelecer relações com a realidade. Em vez de se relacionar com a realidade por meio de uma atitude de abertura possibilitada por conceitos, o sujeito, em sua experiência danificada, emprega, por exemplo, estereótipos (ADORNO, 2003) ou ainda, tal como Adorno indica em seu texto de 1959, Teoria da semiformação, noções ideológicas e superstições (ADORNO, 2010), dentre outras formas equivocadas de pensar a realidade.

Importante, também, é a dimensão da diferença que constitui a experiência, pois pensar é se situar subjetivamente em uma relação dialética com o objeto, o que se apresenta como oposto à identificação com a realidade. Em uma entrevista sobre televisão e formação, de 1963, presente também na edição Educação e emancipação, Adorno se refere ao papel negativo que aquela poderia ter sobre a consciência, contrastando-o, justamente, ao modo pelo qual ocorre a formação. A televisão poderia ser entendida como ideologia na medida em que veicula conteúdos em uma

[...] tentativa de incutir nas pessoas uma falsa consciência e um ocultamento da realidade, além de, como se costuma dizer tão bem, procurar-se impor às pessoas um conjunto de valores como se fossem dogmaticamente positivos, enquanto a formação a que nos referimos consistiria justamente em pensar problematicamente conceitos como estes que são assumidos meramente em sua positividade, possibilitando adquirir um juízo independente e autônomo a seu respeito (ADORNO, 2003, 80).

Esse modo de exercer influência na consciência subjetiva não é exclusividade da televisão, tal como a crítica de Adorno ao fenômeno da indústria cultural deixa claro. Os conteúdos culturais que apresentam versões distorcidas e falsas da realidade comprometem a formação, produzindo imagens harmônicas do mundo, as quais escondem as contradições sociais e tornam os mecanismos de dominação opacos aos indivíduos. Esse modo de operar, que não é apenas formal, produz uma atitude de adaptação ao existente e contém, como será discutido adiante, uma força que nega a democracia. É frente a esse conformismo que a formação pode desempenhar um papel importante. Adorno indica que as instituições são capazes de participar de tal movimento. Em Educação para quê?, ele afirma: "A educação por meio da família, na medida em que é consciente, por meio da escola, da universidade teria neste momento de conformismo onipresente muito mais a tarefa de fortalecer a resistência do que de fortalecer a adaptação" (ADORNO, 2003, 144). Contudo, é preciso 
chamar a atenção para alguns aspectos apontados por Adorno sobre as condições para a formação.

Há algo contido na experiência formativa que escapa a uma simples instrução oferecida por escolas ou universidades. A formação não está ligada, exclusivamente, à presença de determinados conteúdos ou conhecimentos. Sua possibilidade está inscrita também historicamente e é, nesse sentido, que Adorno faz uma crítica à formação que se vincula às origens do próprio conceito. Em Teoria da semiformação, a crítica aos elementos ideológicos contidos no ideal de formação pertencente à classe burguesa é desenvolvida e mostra que as condições objetivas para que um processo formativo tenha lugar requer uma sociedade organizada de modo livre e igual, o que nunca ocorreu. A despeito dessa crítica geral à formação, há outro aspecto a ser destacado que diz respeito ao modo como a formação se desdobra em termos subjetivos. Conteúdos são certamente importantes para que haja conhecimento sobre a realidade, porém, a formação possui uma dimensão afetiva, ligada à constituição do sujeito desde a primeira infância e que, em uma sociedade marcada por diferentes formas de dominação, acaba por reproduzi-las por meio de processos repressivos. Essa adaptação à vida social que se desenvolve a partir da dor e do sofrimento marca o sujeito e estaria ligada, segundo Adorno, a um pseudorealismo presente na sociedade, experimentado por crianças e jovens, e que se manifesta como uma cicatriz.

A ideia de cicatriz é interessante para a reflexão sobre a formação. Ela foi discutida por Horkheimer e Adorno no fragmento "Sobre a gênese da burrice" ao final da Dialética do esclarecimento. Os autores mostram com a figura do caracol, que diante de um obstáculo recolhe suas antenas e se fecha, um exemplo do que ocorre à vida intelectual ameaçada pelo medo, este que também é capaz de paralisar o corpo frente à dor. Para os autores, "na origem, as duas coisas são inseparáveis" (HORKHEIMER; ADORNO, 1985, 239). A experiência com o outro que não ameaça, a experiência de se formar livremente, leva ao desenvolvimento, enquanto seu contrário, a "burrice", apareceria como a cicatriz de quem sofreu ao se expor, que teve a vontade boa transformada em má. Segundo Horkheimer e Adorno, "as perguntas sem fim da criança já são sinais de uma dor secreta, de uma primeira questão para a qual não encontrou resposta e que não sabe formular corretamente" (HORKHEIMER; ADORNO, 1985, 240). A repetição lembraria, por um lado, a vontade lúdica, mas também estaria associada à compulsão desesperada. Se ela cessa porque o desejo foi reprimido, surgem as cicatrizes, as quais deformam o caráter, pois, citando os autores, "elas podem criar caracteres, duros e capazes, podem tornar as pessoas burras - no sentido de uma manifestação de deficiência, da 
cegueira e da impotência, quando ficam estagnadas, no sentido da maldade, da teimosia e do fanatismo, quando desenvolvem um câncer em seu interior" (HORKHEIMER; ADORNO, 1985, 240).

Nas reflexões sobre a educação da década de 1960, essa ideia permanece. Adorno procura mostrar, especialmente em Educação - para quê?, como a formação envolve um momento de espontaneidade, de afetividade, aspectos que se ligarão à constituição do pensamento. Ela envolve elementos involuntários, daí a dificuldade de que se transforme em um projeto pedagógico ou política educacional (ADORNO, 2003). Aqui também há uma referência à ideia de experiência benjaminiana, já que há a presença da memória involuntária, algo que se sedimenta na subjetividade por processos nem sempre intencionais. Ao mesmo tempo em que essa dimensão espontânea caracteriza positivamente a formação, pode ser fonte de bloqueios e obstáculos, impondo ao indivíduo limitações que não são apenas de caráter lógico e formal (ADORNO, 2003), mas relativos à capacidade de reflexão e, sobretudo, de autorreflexão. Em uma passagem do texto A filosofia e os professores, relativo a uma palestra conferida em 1962, Adorno faz o seguinte comentário:

[...] a formação cultural é justamente aquilo para o que não existem à disposição hábitos adequados; ela só pode ser adquirida mediante esforço espontâneo e interesse, não pode ser garantida simplesmente por meio da frequência de cursos, e de qualquer modo estes seriam do tipo "cultura geral". $\mathrm{Na}$ verdade, ela nem ao menos corresponde ao esforço, mas sim à disposição aberta, à capacidade de se abrir a elementos do espírito, apropriando-os de modo produtivo na consciência, em vez de se ocupar com os mesmos unicamente para aprender, conforme prescreve um clichê insuportável (ADORNO, 2003, 64).

Logo adiante, na sequência da passagem mencionada, Adorno ainda indica uma exigência à formação: o amor. ${ }^{8}$ Por ser uma forma oposta à frieza que caracteriza a sociedade burguesa, a qual desencadeia práticas de violência e dominação, associadas à indiferença em relação ao outro, o amor tem papel importante tanto em relação ao ato de ensinar quanto ao de aprender. Adorno afirma que "seria melhor que quem tem deficiências a este respeito, não se dedicasse a ensinar" (ADORNO, 2003, 64). O tema aparecerá também na conferência Educação após Auschwitz e é de extrema importância para a tarefa da não repetição da barbárie. A incapacidade de amar se associa, segundo Adorno, a uma condição psicológica que tornou possível Auschwitz (ADORNO, 2003). Ele a caracteriza como tendência 
geral, ou seja, uma qualidade de caráter de todas as pessoas que vivem nesse momento histórico, no qual a frieza é produzida pelo modo com a sociedade está organizada. O apelo a que se ame, porém, vai contra a própria espontaneidade desse afeto, por isso, não pode ser pregado, e contém um aspecto ideológico e contraditório, porque se torna um dever, revelando, nesse sentido, a frieza de quem ama por obrigação.

Ainda que seja importante para o ensinar e o aprender, o amor, para Adorno, "não pode ser exigido em relações profissionalmente intermediadas, como entre professor e aluno, médico e paciente, advogado e cliente" (ADORNO, 2003, 135). Ele é, entretanto, importante no processo formativo porque propicia a abertura necessária à subjetividade para que se lance à experiência de pensar, de imaginar, de refletir e de se confrontar com a diferença. Como no exemplo trazido pela figura do caracol, aquele que é capaz de amar e ser amado estaria menos sujeito à repressão e, consequentemente, segundo Adorno, mais suscetível a desenvolver o pensamento e, com ele, a autorreflexão. Assim, em vez de prescrever amor, Adorno sugere "ajudar a frieza a adquirir consciência de si própria, das razões pelas quais foi gerada" (ADORNO, 2003, 136).

Observa-se, assim, que a dimensão afetiva é fundamental para a abertura necessária à formação. De modo inverso, em Educação após Auschwitz, Adorno associa ao caráter manipulador justamente a ausência de emoções, a incapacidade de realizar experiências e o realismo que uma educação voltada para a adaptação acaba por promover (ADORNO, 2003). Dessa preocupação advém o olhar de Adorno à primeira infância, quando as interações seriam marcantes para o desenvolvimento do caráter. ${ }^{9} \mathrm{O}$ amor se torna fonte de acolhimento para o medo, em vez de sobre este agir a repressão. Isso se refletiria inclusive no corpo, que se revelaria violento ou que exibiria a marca da violência como produto da repressão que se instalou na consciência (ADORNO, 2003). Ou, ainda, em atitudes ressentidas que se oporiam aos processos formativos, como ele comenta em Educação - para quê? (ADORNO, 2003).

Adorno procura mostrar que a oposição às formas repressivas e violentas não se dá exatamente por meio da tentativa de promover formas positivas, mas começaria pela consciência das razões pelas quais estas são impedidas pela organização social. A formação se mostra, assim, em um movimento duplo que busca promover tanto o reconhecimento de dinâmicas sociais e mecanismos de dominação quanto a influência destes na constituição subjetiva. O elemento reflexivo da formação impulsiona-a a compreender seus próprios limites, os quais podem se expressar, como se refere Adorno, na inaptidão à experiência (ADORNO, 2003, 148). Isso significaria conscientizar-se sobre os elementos repressivos que são 
obstáculos à realização de experiências, na medida em que provocam reações subjetivas, segundo Adorno, de "hostilidade frente à mesma, do rancor frente àquilo de que são privadas. Este teria de ser dissolvido, conduzindo-se as pessoas àquilo que no íntimo todas desejam" (ADORNO, $2003,150)$. Essa relação mais saudável com o próprio eu, que cria um lugar seguro de abertura em relação ao outro, ao que é diferente, permitiria o estabelecimento de relações mais apropriadas com a realidade. Aliado a esse processo, o esclarecimento poderia contribuir para a autonomia tão necessária à resistência contra o autoritarismo.

\section{Crítica e resistência ao autoritarismo}

Ao indicar como tarefa principal à educação evitar a repetição da barbárie, Adorno (2003) sugere, em Educação após Auschwitz, que ela pode ser desenvolvida a partir de duas formas: por uma ação direcionada à infância, dada a formação psicológica importante para a constituição do caráter, e pelo esclarecimento geral, no sentido de se refletir sobre os aspectos, sobretudo psicológicos, que contribuíram para a emergência do totalitarismo - ainda que eles não sejam determinantes para a repetição da barbárie.

Se a ênfase em conteúdos não é o elemento predominante entre as condições da formação, ela é, porém, importante para seu caráter cognitivo expresso na possibilidade de compreensão da realidade. Aspectos psicológicos relativos à constituição do caráter estão em uma relação dialética com as apropriações cognitivas que os indivíduos fazem ao longo de sua formação: um caráter aberto e receptivo à diferença tem mais possibilidades de se formar em termos de uma estrutura autônoma e resistente ao autoritarismo, uma vez que possui disposição para refletir e se relacionar com a realidade conceitualmente. O contrário, indivíduos que tiveram seu desenvolvimento marcado pelo medo e repressão, por exemplo, estariam mais suscetíveis à hostilidade em relação ao conhecimento, o que geraria neles uma forma de pensar limitada, semiformada, que substitui conceitos e a própria reflexão pela imediatidade, seja esta expressa na forma de estereótipos, clichês ou ideologias. Por esse motivo, trabalhar no sentido de dissolver os mecanismos de repressão e também proporcionar uma crítica das ideologias e demais formas equivocadas de se compreender a realidade são práticas condizentes com a formação ou aptidão para a experiência.

Várias indicações de caráter mais específico à educação são bem conhecidas dos leitores de Adorno e são encontradas, principalmente, em Educação após Auschwitz: a ideia de que a educação deve evitar a 
severidade para não reproduzir a violência; de que ela deve também evitar a repressão do medo e outros afetos que ocasionam formas reativas inconscientes prejudiciais à formação; de que a técnica e o esporte constituem instâncias ambíguas que podem impulsionar qualidades de caráter afinadas com traços de violência, o que se refletiria, também, na indiferença em relação ao outro. Para complementá-las, seria interessante observar de modo mais detalhado que elementos presentes na educação atuam na resistência ao autoritarismo, compondo uma espécie de pedagogia democrática. ${ }^{10}$

Tal como em outros momentos da obra de Adorno, a negatividade marca o modo de conceber o trabalho formativo: na impossibilidade de se educar para a democracia, a qual necessitaria principalmente de uma transformação das condições sociais objetivas, a educação atua para, ao menos, intervir naqueles traços subjetivos que poderiam se desenvolver na direção do autoritarismo. Adorno identifica na reação de resistência à democracia um fenômeno vinculado a tendências objetivas. Na palestra $O$ que significa elaborar o passado, ele afirma:

A ordem econômica e, seguindo seu modelo, em grande parte também a organização econômica, continuam obrigando a maioria das pessoas a depender de situações dadas em relação às quais são impotentes, bem como a se manter numa situação de não-emancipação. Se as pessoas querem viver, nada lhes resta senão se adaptar à situação existente, se conformar; precisam abrir mão daquela subjetividade autônoma a que remete a idéia de democracia; conseguem sobreviver apenas na medida em que abdicam seu próprio eu. (...) A necessidade de uma tal adaptação, da identificação com o existente, com o dado, com o poder enquanto tal, gera o potencial totalitário. Este é reforçado pela insatisfação e pelo ódio, produzidos e reproduzidos pela própria imposição à adaptação. Justamente porque a realidade não cumpre a promessa de autonomia, enfim, a promessa de felicidade que o conceito de democracia afinal assegurara, as pessoas tornam-se indiferentes frente à democracia, quando não passam até a odiá-la (ADORNO, 2003,44).

A passagem esclarece a maneira como Adorno compreende a dinâmica entre indivíduo e sociedade, mostrando como a estrutura social impõe restrições à possibilidade de emancipação e, além disso, cria resistência à própria democracia. Na dinâmica por ele exposta, que embora esteja contextualizada na Alemanha do período pós-guerra, ainda é pertinente, a impotência experimentada pelo indivíduo frente à sociedade é 
mal compreendida devido à presença de ideologias. Em função da forma como a subjetividade se constitui nesse contexto, a tendência, conforme argumenta Adorno, é a de que os indivíduos não identifiquem na própria sociedade os problemas que geram sua insatisfação e seu sofrimento. Desse modo, como a realidade é apreendida pelos indivíduos de forma equivocada, a reação afetiva se desloca para o lugar de onde surgiu a promessa não cumprida, ou seja, a própria democracia. Relembrando a passagem de Educação - para quê?, a democracia demandaria pessoas emancipadas para que fosse capaz de cumprir suas promessas, de operar conforme seu conceito. Os indivíduos experimentam o engodo em seu sofrimento e em sua falta de autonomia, porém, a ideologia que sustenta a dominação social impede que as causas objetivas da impotência experimentada e do mau funcionamento da democracia sejam reconhecidas. Como afirma Adorno em uma passagem de $A$ filosofia e os professores que complementa as observações acima,

Onde falta a reflexão do próprio objeto, onde falta o discernimento intelectual da ciência, instala-se em seu lugar a frase ideológica, nos termos do deslumbramento daquela infeliz tradição alemã segundo a qual os nobres idealistas vão para o céu e os materialistas ordinários vão para o inferno. (...) Nesta aliança entre a ausência pura e simples de reflexão intelectual e o estereótipo da visão de mundo oficialista delineia-se uma conformação dotada de afinidades totalitárias (ADORNO, 2003, 62).

É desse modo que a democracia acaba por ser identificada como problema, em vez de a crítica se dirigir à organização social, econômica e cultural que impõem determinadas formas de vida aos indivíduos. Como Adorno defende em $O$ que significa elaborar o passado, em vez de ser concebida como expressão de emancipação, como forma política que se orienta pelas decisões de sujeitos autônomos, a democracia é criticada - e ela deve poder ser criticada-, mas de forma equivocada. Se a democracia não cumpre suas promessas, cabe à crítica buscar identificar as razões para tal. No entanto, para Adorno, se observaria o seguinte fenômeno:

Ela [a democracia] é apreendida como sendo um sistema entre outros, como se num cardápio escolhêssemos entre comunismo, democracia, fascismo ou monarquia; ela não é apreendida como identificando-se ao próprio povo, como expressão de sua emancipação. Ela é avaliada conforme o sucesso ou o insucesso, de que participam também interesses 
individuais, mas não como sendo a unidade entre os interesses individuais e o interesse geral; e, de fato, a delegação parlamentar da vontade popular torna esta muitas vezes uma questão difícil nos modernos Estados de massa (ADORNO, 2003, 35).

A falta de identificação entre o indivíduo e a sociedade democrática aponta para o problema existente na sociedade contemporânea entre formação e democracia. É possível observar na reflexão de Adorno que a impossibilidade da experiência, que se traduz como impossibilidade de uma formação autêntica, compromete a compreensão da realidade e, ainda, cria condições subjetivas para que no lugar da crítica se instalem formas de pensamento inadequadas. Por outro lado, a ideologia que se apresenta na reação de hostilidade dos indivíduos frente à democracia possui um teor de verdade, uma vez que aponta para as contradições que tornam a democracia deficitária em relação aos ideais que ela própria defende. É claro que não bastaria apenas uma melhor formação para que experimentássemos uma democracia mais efetiva, mas sem o elemento formativo ela certamente está impossibilitada de se realizar enquanto desdobramento político da autonomia subjetiva. É nesse sentido que Adorno afirma: "Na linguagem da filosofia poderíamos dizer que na estranheza do povo em relação à democracia se reflete a alienação da sociedade em relação a si mesma" (ADORNO, 2003, 36).

Ao discutir o conceito de emancipação, como já se mencionou anteriormente, Adorno não o faz tratando-o como ideal ingênuo a orientar a educação. Ao contrário, procura indicar que as condições sociais impedem a emancipação, mas que algumas formas de pensar podem, ao menos, apresentar-se como frestas que se abrem a um pensamento não reificado. Em sua dimensão, por assim dizer, negativa e mais relacionada à posição subjetiva, a emancipação se coloca como essa tímida resistência em relação à realidade. Já seu contrário se manifesta como adaptação e identificação cega com o existente, como aceitação da realidade tal como ela se apresenta. Contudo, não se trata simplesmente de opções: a possibilidade de orientar o próprio pensamento e o comportamento está vinculada à constituição da subjetividade. É a compreensão desse vínculo que a formação precisa investigar para melhor orientar-se na tarefa de rompê-lo. Disso decorre que a formação se apresenta como processo e não como objetivo consolidado. Na entrevista Educação - para quê?, Adorno explicita o problema da emancipação em uma sociedade marcada pela contradição:

O motivo evidentemente é a contradição social; é que a organização social em que vivemos continua sendo 
heterônoma, isto é, nenhuma pessoa pode existir na sociedade atual realmente conforme suas próprias determinações; a sociedade forma as pessoas mediante inúmeros canais e instâncias mediadoras, de um modo tal que tudo absorvem e aceitam nos termos desta configuração heterônoma que se desviou de si mesma em sua consciência (ADORNO, 2003, 181).

A formação é fundamental para combater as demais instâncias que podem fortalecer a tendência de adaptação dos indivíduos. E assim como ela é um processo, a própria constituição da subjetividade, ainda que seja, em certos aspectos, enrijecida, sobretudo sua estrutura psíquica, possui aberturas para que mudanças possam ocorrer, como se discutirá à frente.

Trabalhar no sentido da emancipação envolveria desmascarar ideologias, estereótipos e outras formas equivocadas de compreensão da realidade, mas também exigiria o enfrentamento dessa estrutura psíquica associada ao autoritarismo, já que o estranhamento em relação à democracia identificado por Adorno ocorre tanto porque ela é equivocadamente associada às causas do mal-estar experienciado pelos indivíduos, quanto porque as tendências sociais favorecem o desenvolvimento de um caráter manipulador e com traços autoritários. Assim, a relação entre a crise da formação e a democracia também se desdobra nos comportamentos antidemocráticos. Esse traço de caráter revela uma incapacidade de realizar experiências, de estar aberto à diferença e a seu potencial transformativo. Ela é, nas palavras de Adorno, "sobretudo uma consciência que se defende em relação a qualquer vir-aser, frente a qualquer apreensão do próprio condicionamento, impondo como absoluto o que existe de um determinado modo" (ADORNO, 2003, 132). Adorno é relutante na definição, mas afirma em Educação após Auschwitz que tal caráter poderia ser denominado como uma forma de consciência coisificada: "No começo as pessoas desse tipo se tornam por assim dizer iguais a coisas. Em seguida, na medida em que o conseguem, tornam os outros iguais a coisas" (ADORNO, 2003, 130).

Pessoas com essa estrutura subjetiva desenvolvem comportamentos marcados pela frieza, pela incapacidade de amar, e tendem a inverter relações entre meios e fins, como no caso de indivíduos que criam uma relação fetichizada com a técnica, o que, em última instância, aponta para a identificação do indivíduo com elementos irracionais presentes na sociedade, como se pode observar nas reflexões de Adorno em Educação após Auschwitz. Além disso, dada a estrutura de caráter que resulta em um eu fraco, dependente de vínculos com autoridades externas, indivíduos com 
traços autoritários tenderiam mais facilmente a se identificar com figuras de líderes ou com coletivos (ADORNO, 2003).

A preocupação com a permanência desse tipo de caráter leva Adorno a propor que se utilize os métodos científicos para estudar sua gênese e assim compreender as condições psíquicas que foram importantes para a existência de Auschwitz. Contudo, como afirma Adorno,

O perturbador - porque torna tão desesperançoso atuar contrariamente a isso - é que esta tendência de desenvolvimento encontra-se vinculada ao conjunto da civilização. Combatê-lo significa o mesmo que ser contra o espírito do mundo; e desta maneira apenas repito algo que apresentei no começo como sendo o aspecto mais obscuro de uma educação contra Auschwitz (ADORNO, 2003, 133).

Aqui, novamente, observa-se que o papel da educação é bastante limitado, mas que ela deve, ainda assim, se voltar para a constituição da subjetividade como compromisso ético e político de evitar a ocorrência de novas catástrofes. Em Educação e emancipação, debate do qual participou em 1969, Adorno se refere a esse compromisso como a "única concretização efetiva da emancipação", a qual conta com pessoas que assumem a tarefa de conduzir a educação "para a contradição e para a resistência" (ADORNO, 2003, 183). Ele confere aos professores, principalmente, a tarefa de viabilizá-la, levando adiante um projeto pedagógico que se opõe às formas autoritárias dentro da sociedade. ${ }^{11}$ Essa estratégia, que possui um caráter mais individual, se refletiria, também, nas instituições de ensino. Nesse debate de 1969, Adorno oferece vários exemplos de como educadores poderiam atuar em uma espécie de crítica da ideologia, utilizando-se de produtos culturais para identificar neles contradições ou falsidades e, desse modo, promover uma relação modificada em relação à realidade a partir da ruptura com diferentes expressões em que se traduz a dominação na sociedade. Assim, afirma ele:

[...] tenta-se simplesmente começar despertando a consciência quanto a que os homens são enganados de modo permanente, pois hoje em dia o mecanismo da ausência de emancipação é o mundus vult decipi em âmbito planetário, de que o mundo quer ser enganado. A consciência de todos em relação a essas questões poderia resultar de uma crítica imanente, já que nenhuma democracia normal poderia ser dar ao luxo de se opor de maneira explícita a tal esclarecimento (ADORNO, 2003, 183). 
A reação que Adorno imagina surgir frente a esse tipo de iniciativa pode ser pensada como evidência da necessidade de que a crítica imanente, na forma da crítica da ideologia, ${ }^{12}$ deva ocorrer como desdobramento de um projeto pedagógico contra o autoritarismo e suas formas de negação da democracia. Na sequência da passagem acima citada, Adorno comenta que a proposta de analisar criticamente objetos como filmes, por exemplo, sofreria oposição do lobby da indústria cinematográfica que apontaria nessa atividade uma "propaganda ideológica unilateral" (ADORNO, 2003, 183) e prejuízos aos interesses econômicos do setor. Ainda que a afirmação de Adorno seja apenas uma especulação, a qual sabemos hoje não ser algo improvável, ela mostra que a educação transita entre forças políticas que se situam socialmente e economicamente e disputam a formação da consciência. Desse modo, os educadores que selam compromissos com um projeto de sociedade democrática precisam trabalhar no sentido do esclarecimento, não impondo aos estudantes uma determinada interpretação da realidade, o que seria contrário à própria intenção de promover a autonomia, mas revelando, por meio da crítica imanente, as contradições da sociedade. ${ }^{13}$

É interessante notar que no texto Educação e emancipação, Adorno faz uso de uma metáfora instigante para a reflexão sobre a tarefa pedagógica contra o autoritarismo. Adorno se refere à crítica aos produtos culturais realizada junto aos estudantes como forma de "imunizá-los" (ADORNO, 2003, 183). Ao refletirem sobre filmes criados no contexto da indústria cultural, por exemplo, os jovens criariam uma defesa em relação às ideologias neles contidas. Adorno chega a se referir a essa situação dizendo que "é possível torná-los [filmes] infectos aos jovens" e que defenderia a educação nesse sentido de "tornar infecto" (ADORNO, $2003,184)$. Educar utilizando-se da crítica imanente teria o potencial de enfraquecer ou mesmo dissolver a ideologia contida nos produtos culturais de modo a não afetar a consciência de crianças e jovens. ${ }^{14}$

Tal ideia aparece em outro texto de Adorno, o ensaio Democratic Leadership and Mass Manipulation, publicado originalmente em inglês em 1950. Nele, Adorno enfatiza a necessidade de se criar processos para que as ideologias, comportamentos e atitudes sejam desmascaradas em suas contradições. Isso seria feito não simplesmente em um nível discursivo e racional, mas atingindo a dinâmica pulsional do indivíduo. ${ }^{15}$ Adorno utiliza a metáfora da vacina como medida para combater o autoritarismo que ameaça a democracia. Marriotti sintetiza as duas formas interligadas pelas quais essa "vacina" agiria nos indivíduos: 
[...] primeiro, extraindo suas contradições internas e destacando como suas próprias crenças e práticas contêm contratendências que se voltam contra a causa do autoritarismo e em direção à causa da democracia; e segundo, trabalhando com as pessoas, em conversas e diálogos, para criar vacinas a partir de suas próprias patologias, para transformar seus próprios sentimentos de impotência, seus próprios anseios por relacionamentos genuínos - as quais são todas patologias alimentadas pela sociedade de massas moderna - contra o agitador fascista, agora exposto como um manipulador fraudulento (MARIOTTI, 2016, 98).

Tais vacinas teriam alguma eficácia mesmo naqueles que não se mostram tão abertos ao processo de esclarecimento. Como Adorno comenta em Educação após Auschwitz, há pontos de apoio psicológico nos indivíduos que podem ser de alguma forma incitados, como o narcisismo ou o orgulho ( ADORNO, 2003, 131). ${ }^{16}$ Dessa maneira, mobilizando aspectos psicológicos em associação à crítica imanente, como a crítica da ideologia, os processos de esclarecimento poderiam oferecer tensão aos traços autoritários, mostrando, assim, um potencial importante para a defesa da democracia.

\section{Considerações finais}

As reflexões de Adorno sobre a educação presentes nos textos aqui discutidos revelam uma defesa intransigente da autonomia necessária para combater a repetição da barbárie. As propostas pedagógicas que podem ser observadas em suas intervenções levam em consideração o potencial crítico que existe nos indivíduos e que precisa ser mobilizado por processos formativos. É por isso que a educação, embora não seja capaz de promover a transformação das condições objetivas que impedem Auschwitz, pode tentar atuar na subjetividade de forma a conter as tendências autoritárias que se conservam na cultura. A partir dessa aposta, as intervenções de Adorno apontam para dimensões cognitivas e afetivas que compõem a subjetividade e podem ser orientadas para uma direção mais adequada, capaz de se relacionar de forma menos conformista e adaptada diante do existente. ${ }^{17}$

O cuidado de Adorno ao utilizar o termo "educação" e evitar conotações como a de processos de modelagem de pessoas ou de transmissão de conhecimentos, como explica em Educação - para quê?, e sua preferência em associá-lo ao movimento de conduzir a sociedade à emancipação (ADORNO, 2003, 185) apontam para o valor dado à dinâmica 
que constitui a subjetividade e faz dela um movimento constante e reflexivo. A formação encontra na organização social um obstáculo a sua realização e, por esse motivo, o movimento de mediação exigido por ela deve promover a autorreflexão, a compreensão do indivíduo em sua constituição subjetiva, em seus traços que reproduzem a dominação presente na sociedade, bem como a origem social dos males que experimenta.

Assim como a formação encontra limites devido à estrutura e organização social, também a democracia, que demanda um exercício ético e político autônomo dos sujeitos, é impossibilitada de se realizar de forma efetiva. Se a educação não pode contribuir de maneira tão incisiva para o fortalecimento da democracia, pode agir como contraponto às tendências autoritárias e à reificação da consciência. Isso significa que aqueles que conduzem a educação devem assumir o compromisso ético e político pela emancipação:

Numa democracia, quem defende ideais contrários à emancipação, e, portanto, contrários à decisão consciente independente de cada pessoa em particular, é um antidemocrata, até mesmo se as idéias que correspondem a seus desígnios são difundidas no plano formal da democracia. As tendências de apresentação de ideais exteriores que não se originam a partir da própria consciência emancipada, ou melhor, que se legitimam frente a essa consciência, permanecem sendo coletivistas-reacionárias (ADORNO, 2003, 142).

Hoje, ao vermos a emergência de tantas expressões autoritárias em nossa sociedade, as reflexões de Adorno contribuem para lançar uma luz às possibilidades educativas que, inevitavelmente, enfrentam contradições em sua tarefa de conduzir à emancipação. Ao considerarmos as reflexões de Adorno, observamos que o alcance da educação para a transformação social e para a constituição de uma sociedade democrática é bastante limitado. As condições para ambas estão situadas na dimensão objetiva, mas o sujeito, por ser mediado por esta, pode ser uma instância que se opõe às tendências da sociedade. Aqueles que estão envolvidos na tarefa educativa e que reconhecem o valor da democracia como expressão de uma vida emancipada devem assumir o compromisso ético e político de combater as forças regressivas que existem na sociedade. Lembrando as palavras de Adorno, "o único poder efetivo contra o princípio de Auschwitz seria autonomia, para usar a expressão kantiana; o poder para a reflexão, a 
autodeterminação, a não-participação" (ADORNO, 2003, 125), algo que ainda cabe à educação promover quando se dedica à tarefa formativa.

\section{Notas}

1 Professora do Departamento de Filosofia da Universidade Federal de Santa Catarina. Doutora em Filosofia pela Universidade Federal de Santa Catarina (2011), com realização de Doutorado Sanduíche na J.W. Goethe Universität Frankfurt am Main, Alemanha, sob a supervisão do Prof. Dr. Rainer Forst. Doutora em Educação pela Universidade Federal de Santa Catarina (2011). Realizou estágio pós-doutoral (2015) na University College Dublin, Irlanda, sob a supervisão do Prof. Dr. Brian O'Connor.

2 Embora a ênfase das interpretações sobre Adorno se dê nessa direção, o trabalho de Mariotti (2016) propõe uma leitura de Adorno como um teórico da democracia e defensor de uma pedagogia democrática. Para uma abordagem sobre a pedagogia democrática, ver também Januário (2020).

${ }^{3}$ O presente artigo é resultado dos estudos realizados nos últimos anos sobre a relação entre educação e democracia não apenas na obra de Adorno, mas também em Dewey, Nussbaum, Honneth e bell hooks (2013). Embora se procure enfatizar neste texto a importância que a educação apresenta como oposição ao autoritarismo, o artigo não se debruça de forma sistemática sobre o conceito de democracia na obra de Adorno. Se, por um lado, a reflexão de Adorno sobre a democracia se sustenta a partir de um ponto de vista histórico que permite a ele elaborar também críticas à forma que ela assume no contexto da sociedade alemã do pós-guerra, por outro, o conceito de democracia opera normativamente em associação à ideia de emancipação. Nesse sentido, a democracia é considerada como algo que ainda aguarda sua realização e que demanda, por isso, a defesa de suas condições subjetivas inscritas, mesmo que precariamente, no momento presente.

${ }^{4}$ Em seu texto Forever Resistant? Adorno and Radical Transformation of Society, Cooke propõe uma distinção entre as noções de transformação e transformação radical da sociedade. Para ela, Adorno defende a práxis como impulso para a primeira, mas não em relação à segunda, já que ele teria assumido, dentre outras coisas, a imutabilidade das condições sociais objetivas. Essa seria uma das razões para atribuir a ele a postura de resignado. Não é o caso de examinar neste artigo a argumentação construída por Cooke, pois essa discussão demandaria alargar o escopo do presente trabalho. Como contraponto à conclusão de Cooke de que Adorno poderia ser considerado resignado, ver Fleck (2017).

${ }^{5}$ Até mesmo as posições de Dewey e Nussbaum, ao defenderem a importância da educação para a democracia, demonstram preocupações semelhantes: Dewey (1979) entende que a educação é um processo menos influente do que outras formas de apropriação cultural que ocorrem em contextos não formais de educação; Nussbaum (2015), por sua vez, reconhece a importância dos processos 
de formação psíquica da subjetividade e que são a base para um agir de acordo com princípios democráticos.

${ }^{6}$ Adorno se refere, especificamente, às obras $O$ mal-estar na cultura e Psicologia das massas e análise do eu em Educação após Auschwitz (ADORNO, 2003, 120).

7 Há um amplo debate sobre o conceito de formação (Bildung) na obra de Adorno. Algumas posições divergentes no debate internacional são brevemente sintetizadas no artigo de Yacek (2016). No Brasil, é vasta a discussão sobre o tema da educação no pensamento de Adorno, mas seria necessário um trabalho de sistematização das eventuais diferenças de interpretação, algo que foge ao escopo desse trabalho.

${ }^{8}$ Sobre o tema do amor em Adorno, ver Salgado e Vaz (2020) e Kiloh (2019).

${ }^{9}$ Uma reflexão mais detalhada sobre os processos formativos na infância pode ser encontrada em Vaz (2009).

10 Dentre os textos reunidos em Educação e emancipação, a expressão "pedagogia democrática" é empregado por Adorno apenas em "O que significa elaborar o passado" $(2003,45)$.

${ }^{11}$ Conforme Hohendahl, "o projeto pedagógico de Adorno enfatiza a importância individual de professores e estudantes. (...) O que adorno chamou de necessária Entbarbarisierung (desbarbarização) de grandes segmentos da população alemã em 1966 (por exemplo, a população rural) seria realizado por meio de um ensino intensivo mais do que por planejamento burocrático" $(1995,58)$.

12 Neste artigo não se pretende entrar na discussão sobre a concepção de crítica imanente presente na obra de Adorno. Sobre o tema ver, por exemplo, Fleck (2016); De Caux (2021); Nobre (2021).

13 Essa crítica, que assume a forma de crítica da ideologia, denuncia, como bem aponta Fleck, os discursos legitimadores da sociedade: "Uma situação de dominação direta, brutal e absoluta não carece de discurso legitimador, pois o indivíduo dominado não precisa ser convencido de nada, ele obedece apenas por medo das sanções. O surgimento de tal discurso marca, por conseguinte, o início ao menos de alguma forma implícita ou tácita de assentimento. A partir de então, pode-se mostrar tanto que os motivos legitimadores de um ordenamento não são bons, justos, racionais quanto que o estado de coisas aparentemente legitimado não corresponde ao discurso que o legitima. Por conseguinte, a existência de um discurso legitimador, de um discurso que diz que a ordem existente corresponde ao que ela deve ser, caracteriza um momento no qual a crítica social pode passar a ser imanente, no sentido de crítica da ideologia" (FLECK, 2016, 69).

${ }^{14}$ É possível encontrar no debate da obra de Adorno posições divergentes sobre a forma como a educação promoveria uma experiência no sentido mais estrito, ou 
seja, em termos formativos. Stojanov, por exemplo, defende que mesmo produtos da indústria cultural podem promover, ainda que negativamente, elementos para a formação por meio de um processo de crítica sobre eles ou, em outros termos, que a formação poderia ser promovida como superação da semiformação (STOJANOV, 2012). Já Yacek defende que somente a experiência com a alta cultura promoveria uma experiência estética formativa (YACEK, 2016). Dado o recorte do presente artigo, não é possível examinar os argumentos de tais posições. Vale destacar, porém, que há uma diferença entre o que Adorno propõe como um passo em direção à formação pela crítica da ideologia dos produtos culturais e aquilo que ele entende como experiência estética. Sobre o tema, ver também Petry (2015).

15 Essa defesa se relaciona ao que Adorno sustentou no texto "Teoria freudiana e o padrão da propaganda fascista". O fascismo, segundo ele, não teve apoio das massas por recurso a argumentos racionais, mas mobilizando processos irracionais, inconscientes e regressivos (ADORNO, 2015). A educação contra o autoritarismo, embora seja intransigente com a defesa da promoção da autonomia, não significa estar limitada ao âmbito racional, tal como se tenta mostrar neste trabalho, mobilizando, assim, também a dimensão afetiva. A ideia é também defendida por Adorno em Teoria da semiformação (ADORNO, 2010).

16 Essa ideia tem relação com o que Adorno chama de "efeito bumerangue" em "Democratic Leadership and Mass Manipulation": uma forma de usar o movimento do preconceito para dominá-lo; direcionar determinados afetos, os quais podem estar associados a um nível teórico equivocado, para um alvo apropriado, por exemplo, transformando o sentimento de indignação de um indivíduo, que pode ter uma forma preconceituosa, para um alvo que justifique tal indignação (ADORNO, 1965).

17 Como afirmou Adorno em A filosofia e os professores, "Hoje em dia o nazismo sobrevive menos por alguns ainda acreditarem em suas doutrinas - e é discutível inclusive a própria amplitude em que tal crença ocorreu no passado - mas principalmente em determinadas conformações formais do pensamento. Entre estas enumeram-se a disposição a se adaptar ao vigente, uma divisão com valorização distinta entre massa e lideranças, deficiência de relações diretas e espontâneas com pessoas, coisas e idéias, convencionalismo impositivo, crença a qualquer preço no que existe. Conforme seu conteúdo, síndromes e estruturas de pensamento como essas são apolíticas, mas sua sobrevivência tem implicações políticas. Este talvez seja o aspecto mais sério do que estou procurando transmitir" (ADORNO, 2003, 62). 


\section{Referências bibliográficas}

ADORNO, Theodor W. Democratic Leadership and Mass Manipulation. In. GOULDNER, Alvin (ed.). Studies in Leadership: Leadership and Democratic Action. New York: Russell and Russell, 1965. p. 418-438.

ADORNO, Theodor W. Educação e emancipação. São Paulo: Paz e Terra, 2003.

ADORNO, Theodor W. Teoria freudiana e o padrão da propaganda fascista. In. Ensaios sobre a psicologia social e psicanálise. São Paulo: Editora Unesp, 2015. p. 153-198.

ADORNO, Theodor W. Teoria da semiformação. In. PUCCI, Bruno; ZUIN, Antônio Álvaro Soares; LASTÓRIA, Luiz A. Calmon Nabuco (org.). Teoria crítica e inconformismo: novas perspectivas de pesquisa. Campinas: Autores Associados, 2010. p. 7-40.

COOKE, Maeve. Forever Resistant? Adorno and Radical Transformation of Society. In: GORDON, Peter E.; HAMMER, Espen; PENSKY, Max (ed.). Blackwell Companion to Adorno. Hoboken: Wiley, 2019. p. 583-600.

CAUX, Luiz Philippe Rolla de. A imanência da crítica: os sentidos da crítica na tradição frankfurtiana e pós-frankfurtiana. São Paulo: Loyola, 2021.

DEWEY, John. Democracia e educação: introdução à filosofia da educação. São Paulo: Companhia Editora Nacional, 1979.

FLECK, Amaro. Da crítica imanente à crítica do sofrimento: sobre o problema da fundamentação normativa da teoria crítica de Theodor W. 
Adorno. Ethic@ (UFSC), v. 15, n. 1, p. 65-84, 2016. Disponível em $<$ https://periodicos.ufsc.br/index.php/ethic/article/view/16772954.2016v15n1p65/32305> (Acesso em 30 jun. 2021).

FLECK, Amaro. Resignação? Práxis e política na teoria crítica tardia de Theodor W. Kriterion (UFMG), v. 58, p. 467-490, 2017. Disponível em $<$ https://doi.org/10.1590/0100-512X2017n13701am> (Acesso em 30 jun. 2021).

HOHENDAHL, Peter Uwe. Prismatic Thought: Theodor W. Adorno. Lincoln and London: University of Nebraska Press, 1995.

HONNETH, Axel. Educação e esfera pública democrática: um capítulo negligenciado da filosofia política. Civitas - Revista De Ciências Sociais, 13(3), p. 544-562, 2014. Disponível em: <https://doi.org/10.15448/1984-7289.2013.3.16529> (Acesso em 30 jun. 2021).

hooks, bell. Ensinando a transgredir: a educação como prática da liberdade. WMF Martins Fontes, 2013.

HORKHEIMER, Max; ADORNO, Theodor W. Dialética do esclarecimento: fragmentos filosóficos. Rio de Janeiro: Jorge Zahar, 1985.

JANUÁRIO, Adriano. Educação e resistência em Theodor W. Adorno. São Paulo: Edições Loyola, 2020.

KILOH, Kathy J. Adorno's Materialist Ethic of Love. In: GORDON, Peter E.; HAMMER; Espen, PENSKY, Max. (Ed). Blackwell Companion to Adorno. Hoboken: Wiley, 2019. p. 601-613.

MARIOTTI, SHANNON L. Adorno and Democracy: The American Years. Lexington, Kentucky: University Press of Kentucky, 2016.

NOBRE, Marcos. Limites da imanência: um exercício de dialética negativa. Dissonância: Revista de Teoria Crítica, v. 3, p. 1-29, 2020. Disponível em $<$ https://www.ifch.unicamp.br/ojs/index.php/teoriacritica/article/view/409 7> (Acesso em 30 jun. 2021).

NUSSBAUM, Martha. Sem fins lucrativos. Por que a democracia precisa das humanidades. São Paulo: Editora WMF Martins Fontes, 2015.

O'CONNOR, Brian. Adorno. London: Routledge, 2013. 
PETRY, Franciele Bete. Experiência e formação em Theodor W. Adorno. Educação e filosofia. 29(57), p. 455-488, 2015. Disponível em $<$ https://doi.org/10.14393/REVEDFIL.issn.0102-6801.v29n57a2015p455a488> (Acesso em 30 jun. 2021).

SALGADO, Mara; VAZ, Alexandre Fernandez. As faculdades da mimese, imaginação e memória na infância: o entrelaçar do amor e do pensamento. Educação em revista (online), v. 36, p. 1-18, 2020. Disponível em: <https://doi.org/10.1590/0102-4698224960> (Acesso em 30 jun. 2021).

SKIRKE, Christian. After Auschwitz. In. GORDON, Peter E.; HAMMER; Espen, PENSKY, Max. (Ed). Blackwell Companion to Adorno. Hoboken: Wiley, 2019. p. 567-582.

STOJANOV, Krasimir. Theodor W. Adorno - Education as Social Critique. In. SILJANDER, Pauli; KIVELÄ, Ari; SUTINEN, Ari (ed.). Theories of Bildung and Growth. Rotterdam: Sense Publishers, 2012. p. 125-134.

VAZ, Alexandre. Infância, escolarização, semiformação: reflexões sobre a memória e as "expectativas pedagógicas" a partir de Theodor W. Adorno. In. PUCCI, Bruno; ALMEIDA, Jorge de; LASTÓRIA, Luiz A. Calmon Nabuco (org.). Experiência formativa e educação. São Paulo: Nankin, 2009. p. 5367.

YACEK, Douglas. Dialectics of Education. Adorno on the Possibility of Bildung in Consumer Society. Philosophy of Education (Urbana, IL). p. 204-213.

Disponível

em

$<$ https://educationjournal.web.illinois.edu/archive/index.php/pes/article/v iew/5262.pdf> (Acesso em 30 jun. 2021). 